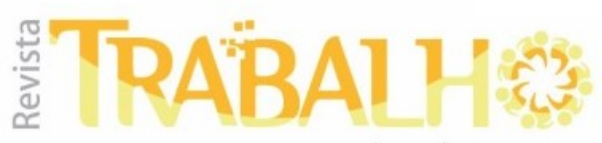

(En)Cena

\title{
NOTAS PARA UMA DEFINIÇÃO ANTROPOLÓGICA SOBRE A RELAÇÃO ENTRE TRABALHO E MASCULINIDADES ${ }^{12}$
}

Notes for an anthropological definition about the relationship between work and masculinities

Notes pour une definition anthropologique du rapport travail - masculinites

Notas para una definición antropológica acerca de la relación entre trabajo y masculinidades

Hernán M. Palermo ${ }^{3}$

Doutor em Ciências Antropológicas. Investigador do Centro de Estudos e Investigações Laborais (CEILCONICET-Argentina). Diretor da Revista Latino-americana de Antropologia do Trabalho pertencendo ao CEIL da Argentina e ao CIESAS do México.

\begin{abstract}
Resumo
A pergunta que guia este escrito é como se produz e reproduz a força do trabalho no modo de produção capitalista. Essa Pergunta nos vincula diretamente com as formas que desdobra o capital para adequar a força de trabalho aos seus objetivos de valorização, acumulação e reprodução. Nesse sentido, e também nesse ensaio, nos interessa abordar a forma em que o capital é dotado de valor, porém, sobretudo como esse processo entranha articulações de sentidos entre a construção da masculinidade e o trabalho. No marco desse enfoque, nos interessa dar ênfase na importância dos estudos de casos, abordagens que permitem analisar as relações de poder que se manifestam em processos sociais e culturais, assim como pensar nos sujeitos de carne e osso. Por outro lado, recuperamos diversos estudos sobre as masculinidades. A final, trazemos a análise dos estudos de casos investigados por nós: os trabalhadores petroleiros e os trabalhadores da indústria de software.
\end{abstract}

Palavras Chaves: Trabalho; Masculinidade; Petroleiros; Software.

\begin{abstract}
The question that guides this writing is how the work force is produced and reproduced in the capitalist mode of production. This question links us directly to the forms that capital deploys to adapt the work force to its valorization, accumulation and reproduction objetives. To this respect, in this essay, we are interested in studying how the capital is endowed with value and specifically how this process links articulations of meanings between the construction of masculinity and work. Within the framework of this proposal, we are interested in emphasizing the importance of case studies, approaches that allow us to analyze the power relations that are manifested in social and cultural processes, as well as to think about the subjects of flesh and blood.Otherwise, we consider many studies related to masculinities research. In the end, we bring to the analysis two case studies investigated by us: oil workers and workers in the software industry.
\end{abstract}

\footnotetext{
${ }^{1}$ Uma versão preliminar desse artigo foi parte da Conferência intitulada "Produção de masculinidades no trabalho: hegemonia empresária, disciplina fabril e a construção do gênero". Fez parte da Abertura do $4^{\mathrm{a}}$ Simpósio sobre "Trabalho, Atividade e Subjetividade", nos dias 17 e 18 de maio de 2018 na Faculdade de Psicologia, da Universidade Nacional de Córdoba, Argentina.

2 Este artigo foi traduzido do espanhol para o português por Carmen Moreno Magraner, email:carmenmm27@hotmail.com

3hernanpalermo@gmail.com
} 
Keywords: Work, Masculinities, Oil workers, Software.

\section{Resumen}

La pregunta que guía este escrito es cómo se produce y reproduce la fuerza de trabajo en el modo de producción capitalista. Este interrogante nos vincula directamente con las formas que despliega el capital para adecuar la fuerza de trabajo a sus objetivos de valorización, acumulación y reproducción. En este sentido, en este ensayo, nos interesa abordar la forma en que el capital es dotado de valor, pero sobre todo cómo ese proceso entrama articulaciones de sentidos entre la construcción de la masculinidad y el trabajo. En el marco de este planteo, nos interesa hacer hincapié en la importancia de los estudios de caso, abordajes que permiten analizar las relaciones de poder que se manifiestan en procesos sociales y culturales, así como pensar en los sujetos de carne y hueso. Por otra parte recuperamos diversos estudios acerca de las masculinidades. Al final, traemos al análisis dos estudios de caso investigados por nosotros: los trabajadores petroleros y los trabajadores de la industria del software.

Palabras Claves: Trabajo; Masculinidad; Petroleros; Software

\section{Résumé}

Comment la force de travail est produite et reproduite dans le mode de production capitaliste est la question qui guide cet article. Elle nous met directement en rapport avec les formes que le capital déploie pour adapter la main-d'œuvre à ses objectifs de valorisation, d'accumulation et de reproduction. En ce sens, nous nous intéressons dans cet essai à la façon dont le capital est doté de valeur, mais surtout comment ce processus tisse des articulations de sens entre la construction de la masculinité et le travail. Dans ce cadre, nous mettons en avant les études de cas, approche qui permet d'analyser les relations de pouvoir qui se manifestent dans les processus sociaux et culturels, ainsi que de penser aux sujets en chair et en os. D'un autre côté, nous récupérons diverses études sur les masculinités. Finalement, nous analysons deux études de cas menées par nous: les travailleurs du pétrole et les travailleurs de l'industrie du logiciel.

Mots-clé: Travail; Masculinité; Pétroliers; Logiciel.

\section{Introdução}

Uma das perguntas que inquieta ao que podemos denominar como Estudos Críticos do Trabalho são como se produz e reproduz a força de trabalho no modo de produção capitalista. Pregunta que, pese a diversos enfoques que tentaram superar este tipo de problemáticas e arquivar de uma vez e para sempre estas preocupações no baú de recordações, segue sendo pertinente para compreender uma sociedade com permanentes antagonismos.Uma sociedade intrinsecamente conflitiva que como consequência se renova constantemente de maneira dinâmica. Emergem assim, configurações processuais e variações de contradições que se recombinam em forma assídua e dialética com a luta de classes, transformando condições objetivas e subjetivas. Esse interrogante nos vincula diretamente com as formas que desdobra o capital para adequar a força de trabalho a seus objetivos de valorização, acumulação e reprodução. Vocação que de modo algum é uma novidade, senão que se configura como parte dos processos históricos como 
modo de produção capitalista desde o mesmo momento de acumulação originária, entrelaçando lógicas de invisibilizaçãoou mais apropriado processos de fetiches.De qualquer modo, o reto para os/as investigadores/as é advertir que já não é possível dar com nenhum tipo de resposta plausível desse tipo de interrogante se não compreendemos que gênero e classe ou classe e gênero constituem colaboração imprescindível para entender como se organizam as disputas e relações de poder na sociedade ocidental e capitalista e, em particular, nos âmbitos laborais. Isso é importante enfocálo, tendo em vista que na atualidade no interior do marxismo continua sendo reproduzido um debate "bizantino" a respeito de qual seria a principal contradição: $\mathrm{Se}$ a classe ou $\mathrm{o}$ gênero.Debate que ao nosso entender deixa debilitado o feminismo, principalmente autoras como Iris Young (1992) e Silvia Federici (2014) entre outras.A luta de classes segue sendo clave para entender o conflito, a disputa de interesses em uma sociedade de classes.A pesar disso, devemos enfatizar que não é possível tornar absoluto a luta de classes como paradigma explicativo.Porém é possível ver o impedimento na articulação de uma multiplicidade de relações sociais que existe no marco de uma sociedade crescentemente complexa e onde, justo como enfoca Joan Scott (2008), as tramas de sentido na qual se entrelaçam a masculinidade e a feminidade como categorias opostas, binárias e hierarquizadas constituem as formas simbólicas de poder mais resistentes, recorrentes e arraigadas em nossas sociedades ocidentais.

É por isso que, nesse ensaio, nos interessa abordar a forma em que o capital é dotado de valor, mais, sobretudo como esse processo entrelaça articulações de sentidos entre a construção da masculinidade e o trabalho. E aqui sublinhamos duas palavras chaves que de certa forma estruturam toda a exposição do presente escrito: trabalho e masculinidade.

Ambas as categorias são pontas de iceberg de debates, discussões e tensões que nutrem em grande medida este escrito.

No marco desse enfoque, no presente ensaio recuperamos investigações da antropologia do trabalho. Sobretudo nos interessa dar ênfase na importância dos estudos de casos, abordagens que permitem analisar as relações de poder que se manifestam em processos sociais e culturais, assim como pensar nos sujeitos de carne e osso. Por outra parte, recuperamos diversos estudos a respeito das masculinidades, que nos dão ferramentas teóricas para observar a relação entre gênero e trabalho. A final, trazemos a análise dos estudos de casos 
investigados por nós: os trabalhadores petroleiros e os trabalhadores da indústria de software. Para o primeiro caso, realizamos um exaustivo trabalho de campo com trabalhadores petroleiros e suas famílias na cidade de Comodoro Rivadavia, localizada na Patagônia Argentina. Para o caso dos trabalhadores de sexo masculino da indústria do software nos embasamos em um trabalho de campo de um ano, em particular em duas grandes empresas transnacionais de software, Google e Mercado Livre, ambas localizadas em bairros da Cidade Autônoma de Buenos Aires.

A comparação entre ambas as investigações nos permitiu delinear a respeito de como se configuram as relações de poder no trabalho e, sobretudo pensar nos processos de formaçãoda força laboral.

\section{Os estudos de antropologia do trabalho:} algumas contribuições importantes

Com respeito à noção de "trabalho", encontramos toda uma tradição crucial desde a sociologia, na qual se destacam alguns autores. Braverman como importância preocupou-se com os estudos do trabalho e exercício dos mecanismos de controle. Argumentou que quando o capitalista compra distintas mercadorias como maquinário, ferramentas, etc., podem avaliar o gasto, o rendimento, a vida útil, o custo e a depreciação. Mas quando compra e consome força de trabalho a única mercadoria capaz de gerar novo valor os cálculos estão longe de serem precisos e exatos. É por isso que é essencial para o capital que o controle do processo de trabalho seja afastar do trabalhador, e é aqui onde surge o problema da administração empresária. Em definitivo, para analisar as experiências obreiras, é necessário compreendê-las em relação às formas de uso e valorização do trabalho e como estas formas expressam uma determinada organização empresarial(1974: 75). Nessa linha de preocupações, recuperamos a Burawoy (1989), quemaborda o conceito de consentimento para tentar explicar os motivos que levam aos trabalhadores a produzir por cima de suas capacidades físicas, favorecendo a acumulação capitalista. Menciona que além dos processos de coerção existe, fundamentalmente, consentimento na constituição dos coletivos de trabalhadores/as. A pergunta que motiva ao sociólogo norte americano é: Porque os trabalhadores e as trabalhadoras colaboram ativamente na sua própria exploração realizando seu labor por cima de suas condições físicas?

Em uma tentativa de configurar uma teoria desde o marxismo, articulando conceitosfoucaultianos, tomamos os escritos de Gaudemar (1991). O autor 
reconstrói uma genealogia dos ciclos disciplinares, para poder compreender o desdobramento de políticas empresárias que moldam os coletivos de trabalho. É interessante nesse autor sua proposta sobre como as políticas empresárias se modificam retomando a metáfora de Clausewitza respeito da guerra de acordo as resistências que oferecem as práticas dos trabalhadores em massas refratárias. $\mathrm{Na}$ sua obra encontramos expressas as contribuições de Braverman, ao se referir na busca contínua por parte da administração empresária do controle do obreiro ou, retomando suas palavras, a consolidação da "habituação do trabalhador".

Pero especificamente nos interessa recuperar uma tradição desde a antropologia do trabalho para nutrir nossa proposta, que na América Latina evidencia importante colaboração, para poder pensar o trabalho em debate com outras disciplinas como a sociologia, a história, a economia política e a educação, entre outras.

A antropologia do trabalho tem a potencialidade de promover interrogantes a respeito da situação da classe obreira na América Latina e contribuir à problematização dos processos de produção e reprodução da força de trabalho. E é desde a antropologia que podemos perguntar novamente e questionar categorias cristalizadas de maneira sem crítica nas ciências sociais do trabalho, como homogeneidade/ heterogeneidade,formal /informal,precário/ não precário,trabalho típico /trabalho atípico,obreiro/camponêsou a noção sacrossanta de "sociedade salarial". Estas categorias nos levam a recortar e simplificar a complexidade da realidade latino americana, firmada por processos desiguais de industrialização, de sindicalização, de avances dos processos de terceirização e de tradições de luta e organização sindical, social, social e política das/dos trabalhadores tanto em zonas rurais como urbanas. Conforme enfocouoantropólogo mexicano ÁngelPalerm (1980:33): “Os processos da história se realizam de maneiras mais complexas, marcham por caminhos mais desonestos e levam finalmente a soluções mais astutas que aquelas que sugerem qualquer desajeitada simplificação". Nesse sentido, a antropologia do trabalho nos permite aprofundar os estudos com pessoas reais de carne e osso, onde os enfoques teóricos - metodológicos se fundamentem em estudos de casos, em pautas "registráveis", para abordar relações de poder e esclarecer aqueles memorandos que prescrevem práticas e representações nos sujeitos, mais que também sofrem modificações e reinterpretações. 
Uma das contribuições da antropologia do trabalho foi de analisar as digitais dos processos de trabalhos nos espaços da reprodução dos trabalhadores e trabalhadoras. Das produções brasileiras, destacamos o trabalho de José Sergio LeiteLopes, quem analisa como o controle dentro dos ingênuos açucareiros no nordeste do Brasil traspassa os espaços do trabalho "enraizando-se" em todos os espaços da vida dos trabalhadores. Essa "invasão" do trabalho na área doméstica, dirá LeiteLopes, forma os cimentos do cativeiro dos trabalhadores (2011:133). O Vapor do Diabo, principal obra de LeiteLopes, desvela as formas que adquire o processo de denominação o espaço da reprodução dos trabalhadores.

Assim, as representações e práticas sociais dos trabalhadores se veem atravessadas pelos interesses empresários que transbordam o espaço da fábrica e se situam em todos os aspectos da vida cotidiana. Aqui é fundamental assinalar que não havia maneira de aceder a essa duplicidade e inversão de significados se não é mediante uma abordagem etnográfica baseada em um trabalho orientado para compreender as representações dos trabalhadores a respeito de suas práticas. Desse modo a perspectiva etnográfica assumida pelo autor entende a organização do trabalho industrial e a organização do espaço da reprodução desde o ponto de vista dos trabalhadores inseridos em um processo de denominação ${ }^{4}$. Outra investigação que trazemos é a que realizaGustavo Lins Ribeiro, quem desde as categorias de "projetos de grandes sobras" nos outorga elementos substanciais para abordar a conformação de empreendimentos de grande envergadura, que mobilizam um grande fluxo de força de trabalho. Nesse sentido, o autor analisa a construção da capital Brasília (Ribeiro, 2006) e em outra investigação a construção e posta em andamento a represa argentina-paraguaia Yacyretá (Ribeiro, 1991). Em ambas se observam aspectos ideológicos como o nacionalismo ou o projeto pioneiro que toda "grande obra" sintetiza, confundindo dessa maneira as relações de denominação nos espaços de trabalho, uma vez que potenciam os interesses empresariais e imprimem toda uma dinâmica fora do espaço laboral condicionada particularmente pelos ritmos produtivos. Estas investigações põe de destaque a articulação de estratégias empresariais de fixação e/ou transitoriedade da força de trabalho em tais projetos, aos quais requerem mobilização de amplos

\footnotetext{
${ }^{4}$ No mesmo sentido se enfoca o trabalhode Neiburg (1988) e suaanálise do sistema de "fábricavilaobreira" na empresa Loma Negra, Argentina. Esta última investigaçãoanalisou de maneiradetalhada a configuração dos bairrosobreiros a partir das hierarquiaslaborais conforme foifeita por LeiteLopescom os trabalhadores do açúcar.
} 
contingentes obreiros nos momentos de construção e $\operatorname{logo}$ a expulsão de trabalhadores uma vez terminada as obras. $\mathrm{O}$ isolamento da zona eleita tanto em términos geográficos como de sua grandeza, constituem duas características estreitamente vinculadas entre si. Ambas explicam as condições objetivas que, somadas, determina que o território da construção adquira aspectos de enganos onde a subordinação dos indivíduos em seu cotidiano obedece aos interesses vinculados à construção.Outra investigação que forma parte no nosso enfoque é o trabalho de CorneliaEckert sobre os mineiros do carvão de França. Sua investigação parte das noções de memória e trabalho, para chegar aos processos vivenciais dos trabalhadores a respeito do passado. O “Tempo da Companhia" é evocado pelos trabalhadores aposentados como um tempo idealizado, sobretudo em contraste com o presente, onde a empresa alcançava com suas políticas todos os interstícios da vida dos trabalhadores e seus familiares.

A antropologia em México penetrou nos estudos industriais partindo da região, comunidade e família como unidade de análise para entender as rupturas e continuidades dos processos de trabalho na cotidianidade dos trabalhadores. Nesse sentido, também focado nos estabelecimentos mineiros, o antropólogo Juan LuisSariego Rodríguez (1988) analisa minuciosamente a dinâmica das políticas empresariais no México a início do século XX. Estas políticas empresariais incorporavam o princípio de descriminação étnica como estratégia de denominação da força de trabalho. Isso quer dizer que sobre a base da diferenciação da nacionalidade mexicana, norte americana e china e a etnia dos trabalhadores, ativam-se uma prática empresarial que divide, segrega e fragmenta através dos requerimentos do processo produtivo. A diferença na nacionalidade ou etnia dos trabalhadores traduz e expressa inserções laborais diferenciadas que implicam hierarquização e diferenciação nas condições de trabalho e de vida dos trabalhadores. Aqueles de procedência china e norte americana acedem a melhores postos remunerados e com capacidade de comando, enquanto que os mexicanos e os trabalhadores de ascendência étnica são destinados a piores postos remunerados e impossibilitados de uma progressão social. Como bem detalha o antropólogo, configura-se uma predeterminação laboral em relação à procedência territorial social dos trabalhadores e uma configuração territorial dos bairros a partir das procedências étnicas.

$\mathrm{Na}$ Argentina, diversas etnias situadas em empresas petroleiras (Palermo, 
2012) e siderúrgicas (Soul, 2014) desenvolvidas durante grande parte do século XX se dão conta de como o desenho urbano dos bairros construídos pelas empresas direcionava aos trabalhadores em função de suas qualificações, estabelecendo âmbitos de residência e sociabilidade diferenciados para os operários a respeito dos profissionais com capacidade de comando.

Em outras latitudes, June Nash (2015) realizou contribuições de relevância ao analisar a conformação da hegemonia corporativa empresarial no nível das localidades onde se encontram as grandes empresas. A antropóloga norte americana incorpora a classe obreira como sujeito criativo, ativo, partícipe na consolidação dos interesses empresariais. Em sintonia com o que foi dito a respeito das investigações aqui sinaladas, aborda as estratégias de fixação e/ou transitoriedade da força de trabalho no fordimo e nas atuais formas de organização laboral.

Como está expresso nas contribuições da antropologia do trabalho, "a vocação formadora do capital" transborda os espaços laborais e ancoram os territórios articulando a cotidianidade dos trabalhadores e suas famílias. Entretanto, pese a constituir importantes contribuições, vale dizer que pouco ou quase nada foi analisado sobre a maneira em que seja "vocação formadora" configuraeconsolidam sujeitos cordiais. Salvo alguma exceção na qual situamos June Nash, a antropologia do trabalho analisou pouco desde um olhar de gênero. Em consequência, partindo dos estudos de casos que desde a antropologia se propõem, recuperamos as investigações que abordam e problematizam as masculinidades.

\section{Alguns estudos de masculinidades}

Resulta imprescindível recuperar os estudos sobre masculinidade. Os últimos anos viram a emergência de diversos movimentos feministas que, desde o ponto de vista do gênero, problematizam os orçamentos em que se fundam as hierarquias a partir da divisão dos sexos. De forma que o gênero, como perspectiva dentro das ciências sociais, converteu-se em um campo fértil e especializado com amplio consenso na comunidade acadêmica e inclusive indo mais além dessa. Um campo de estudo que, com seus matizes e variantes, empreende distintas problemáticas. Durante os anos 80 nos países anglo-saxões uma corrente de estudos que se situa o olhar no Homem como posição de gênero. Com a denominação de Men'sstudies, emerge una série de investigações que tem como objeto de problematização ao homem em suas variadas dimensões. $\mathrm{O}$ que os Men'sstudiespodem principalmente em 
questão é a idéia de pensar um modelo de ser homem vinculado à noção de homem patriarcal. Vão a enfocar que não existe uma masculinidade, senão múltiplas e variadas masculinidades (Kimmel, 1997). Situam a produção de "virilidade" como parte de processos culturais: quer dizer, as maneiras de "ser homem" são variadas e heterogêneas e se constituem como fenômenos sociais e históricos (Gilmore, 1994; Laqueur, 1994). Os Men'sstudiesse multiplicaram em investigações orientadas em pôr em evidência empiricamente as heterogêneas formas que adquire a masculinidade em distintos contextos. RaewynConnell (1995) propõe um marco teórico-metodológicopensando nas formas da masculinidade hegemônica. Nesse sentido, enfoca que os modelos hegemônicos de masculinidade funcionam como modelos aspirantes, quase que não alcançáveis.

Essas premissas sobre as diversas formas de ser homem e a possibilidade e a impossibilidade de falar de masculinidade em singular, impulsionaram importantes contribuições na América Latina. Vários estudos afirmaram que não é apenas necessário abordar as masculinidades desde uma perspectiva de classe, senão também a partir de uma relação geral, de etnia e região, para aceder uma compreensão particular tanto histórica como social (Bastos, 1998; Fonseca,
2003). A respeito às contribuições foram significativas: ressaltamos a análise deMara ViverosVigoya (2001) em Colômbia e Norma Fuller (1997) emPeru e sua investigação sobre a classe média ilustrada, intelectual e profissional desse país. Fuller apresenta um conceito que ressaltamos para pensar as masculinidades: o miserável. O miserável é o negativo contra o qual se desenha o exercício da masculinidade. $\mathrm{O}$ feminino atua como uma fronteira desprezível do masculino, uma constante recordação na qual gera rejeição compulsiva e que define que dessa maneira não tem que ser.

\section{Uma proposta analítica entre a antropologia do trabalho e os estudos de masculinidades:}

\section{$\underline{\mathrm{O} \text { caso dos petroleiros da Argentina }}$}

O caso de estudo que abordamos foi dos petroleiros na Argentina (Palermo, 2017). Em nossa investigação, sustentada em um estudo de casos, apresentamos que as políticas empresariais dinamizam noções que configuram posições de gênero nos trabalhadores/as. Dito de outra maneira e complicando essa afirmação, as políticas empresariais interpelam uma particular disciplina fabrilque mobiliza determinadas noções de gênero, em nosso caso um modelo de masculinidade. A noção de disciplina fabril se ancora em uma 
concepção gramsciana para pensar na produção e reprodução da força de trabalho, quer dizer que, na vocação formadora do capital configuram-se sentidos, valores, representações e práticas a partir da coerção e o consenso. Dessa forma, as políticas empresariais amoldam hábitos, atitudes, costumes, práticas. Nesse processo configuram-se formas legitimadas de como se comportar como homens: no universo do petróleo, "a fortaleza", "a resistência", "a paciência" e "a perseverança" são valoresrequeridos, avaliados e interpelados no espaço de trabalho. Significa que, a masculinidade culmina sendo uma ferramenta a mais para o desempenho laboral, sujeito a avaliação. Logicamenteas maiorias dos homens estãoformatados para uma socialização onde a masculinidade se concretana subordinação da feminidade (retomando a idéia do "miserável" de Fuller), mais esses atributos dos quais somos portadores encontram um processo de maximização no trabalho petroleiro a partir da racionalidade instrumental das políticas empresariais.

Alguns autores que analisam o universo das forças armadas apresentam que nessas instituições prefiguram-se um modelo hegemônico ao redor de uma "masculinidade heróica". Figueroa Perea (2005) é quem investiga as formas da constituição da masculinidade em instituições militares da América Latina. O autor analisa o chamado "mito do herói", na qual muitos homens aprendem a serem heróis e gerar histórias de risco para logo contar aos seus pares, inclusive chegando a arriscar sua própria vida. Em sintonia com o que foi dito anteriormente, Michael Kaufman (1995) propõe que o poder que possuem os homens resulta em privilégios (isso é indiscutível), entretanto, alimenta também experiências de sofrimento pelos imperativos na qual estão expostos. Retomando essas idéias, para o caso dos petroleiros argentinos que analisamos, existe uma relação entre os acidentes e o imperativo da masculinidade: os homens são interpelados a serem resistentes, a suportar os golpes e isso se evidencia em seu ocultamento quando ocorre sucede, na relativização de sua importância ou nos relatos heroicos de haverem estado perto da morte. É frequente escutar no trabalho dos petroleiros tais como "não pode reclamar por um triz", ou "isto não é uma escola de senhoritas”, ou "tal raspão não cabe denúncia", ou "essa marca de um golpe é como uma medalha", etc. Os imperativos de masculinidade operam na relativização dos acidentes e nos prêmios que é cobrado em cada equipe de trabalho por não haver "sucedido" (nesses casos são ocultados) acidentes. Como não é uma "escola de senhoritas", os homens suportam os acidentes como marcas de 
guerra que podem ser exibidas como medalhas. Essa demonstração de masculinidade tem sua contrapartida na minimização dos acidentes como "coisinhas". Dessa maneira fortalece uma disciplina fabril que, na sua prática cotidiana, ignora os acidentespara que não seja parado o trabalho. A virilidade, a capacidade de suportar golpes, raspões e cortes, pode vir a ter um índice de medição quantificável a partir das marcas nas mãos dos petroleiros. $E$ as marcas não são exibidas apenas perante o investigador que pergunta, senão que também são ostentadas dentro do grupo de trabalhadores com os signos de virilidade. São como as medalhas penduradas no peito, signos de masculinidade quantificável.

Outro aspecto desse sofrimento tem relação com a volta ao lar despois de estar embarcado na extração de petróleo. $\mathrm{O}$ sofrimento faz-se presente fora do trabalho na ausência dos trabalhadores na vida familiar. Aparecem os relatos dos trabalhadores homens atado a idéia de perda ou a frustação de não compartilhar o tempo com sua família. Ao retornar as suas casas os homens entram em seu universo com códigos, linguagens e dinâmicas completamente diferentes aos do mundo petroleiro caracterizado pelo homo sociabilidade. Depois de 14 dias de trabalho em um universo monopolizado por atividades laborais e significantes masculinos, o espaço doméstico se apresenta como alheio. Em suas casas os homens mergulham em uma dinâmica completamente estranha do mundo laboral. Alguns trabalhadores de sexo masculino se sentem estranhos em seu próprio lar. Os turnos são rotativos, o trabalho é de noite e o descanso é diurno, ao contrário de toda a família, e os hábitos que estão acostumados os homens levam a uma constante tensão. A construção da masculinidade no seno da organização do processo de trabalho petroleiro colide com certas dinâmicas da esfera doméstica, como parte da dicotomização binária entre a masculinidade e a feminidade.

Claramente podemos afirmar que existe entre a masculinidade e sua exacerbação uma profunda relação com os processos de precarização da vida dos trabalhadores do sexo masculino. À medida que se exacerba a masculinidade mais expostos ficam os homens, não somente no espaço de trabalho, senão a sua volta no espaço fora do mesmo. E também é possível estender uma ponte entre a exacerbação da masculinidade e a perda de direitos laborais: um claro exemplo é o convênio coletivo de trabalho que foi negociado para os petroleiros que trabalham na jazida de shaleoildenominada"Vaca Morta"na província de Neuquén. Nessa localidade 
entre2016 y 2017 foi renegociado o convênio coletivo gerando um forte retrocesso em direitos adquiridos pelos trabalhadores do petróleo. Entre os retrocessos figura, por exemplo, a possibilidade de realizar por parte de um trabalhador simultaneidade de tarefas: montagem e desmontagem de equipes em horários noturnos, trabalhos de quadrilhas pese a estar incompleta, continuidade do trabalho apesar das condições climáticas, entre outras situações que antes dessa nova negociação estavam proibidas. Nesse contexto de retrocesso de direitos, inversamente se vê favorecido um ethos de masculinidade que interpela aos trabalhadores ao perceber essas regressões em direitos como questões menores.

\section{$\underline{\mathrm{O} \text { caso dos programadores da indústria do }}$} software na Argentina

Existem espaços de trabalho onde a disciplina fabril fortalece outro tipo de imperativos de masculinidade radicalmente oposto ao que analisamos no mundo do petróleo: referimo-nos a indústria do software. Nessas fábricas de "bens informacionais $^{5}$ se configura uma particular construção a respeito da masculinidade, dado que é um trabalho em

${ }^{5}$ Bens informacionaissão aqueles feitos de informação digital. Fazemos referência a bens que se produzem, por exemplo, com um PC e estão feitos puramente de bits: textos, programas de computador, comunicações digitais, áudio, entre outros. que não é necessário o esforço físico, a resistência, a fortaleza, conforme o que analisamos no caso anterior.Ao contrário, predomina uma "cultura jovem" sempre renovada eaté omomento infantilizado. $\mathrm{La}$ vinculação profunda com a tecnologia demanda "jovens talentosos", mais a idéia de jovem não está apenas na idade vital de um trabalhador/a. As empresas seduzem a esses trabalhadores/as não apenas pelos salários que em alguns casos são baixos em comparação aos de outros empregos e, sobretudo aos petroleiros senão pelas políticas de políticas de benefícios que outorgam aos seus empregados/as. A Maioria dos trabalhadores/as que desempenham a função de programadores na indústria do software de sexo masculino ${ }^{6}$.

Nesses âmbitos de trabalho persiste umethos da masculinidade apropriado e exercício pelos trabalhadores do software, na qual transtorna modelos tradicionais. A indústria do Software tem particularidades

\footnotetext{
${ }^{6}$ Alguns autores/as ao tentar dar resposta a essa situação, enfocam que escassa participação de mulheres como programadoras se deve a diversas questões: por um lado, o acesso diferencial entre homens e mulheres a tecnologia como atividade lúdica desde o início da infância, sobretudo o que se relaciona com videogames (Mura,YanseneZukerfeld, 2012); tambémacontece que as empresas estruturam postos diferenciados genericamente, onde as mulheres acedem ao que é atenção aos clientesou suporte técnicoque implica dessa forma atenção. Por outra parte, o trabalho de programadoré uma atividade com uma alta rotação. Essa característica é um problema para aquelas mulheres que optam pela maternidade em algum momento de sua vida.
} 
complexas na sua organização de trabalho, que não será possível vê-las todas nesse artigo. Mas é relevante sinalar para nossos propósitos comparativos que o trabalho se organiza em equipes pequenas interconectadas, onde a "criatividade" é o motor que faz girar a produção. Essa característica do processo produtivo produz tensões no interior das empresas, no marco de um alto grau de aleatoriedade e incerteza. O trabalho está associado a "criatividade" e, nesse sentido, está sujeito a maiores erros e vicissitudes que outros trabalhos e, sobretudo a um difícil controle nos tempos de produção. A formação deBraverman -“o capitalista quandocompra e consome força de trabalho os cálculos estão longe de serem precisos e exatos" (1974: 75)- encontra sua mais acabada expressão nessa indústria criativa. Por isso a importância que adquirem chefes de equipes no processo de trabalho, pois não somente devem ter um profundo saber técnicoprofissional, senão que também o que se denomina cotidianamente na indústria como comosoftskills. Esses são "saberes leves" que se encontram orientados sobretudo no manejo das equipes. E dentro das qualidades centrais que um chefe de equipe deve ter, encontrase o saber de o que "pensam" e o que "sentem" os integrantes de sua equipe. É informação vital para a correta planificação criativa e coletiva, e para a concretização dos objetivos. Não resulta casual que nas entrevistas, os chefes explicitem que uma de suas tarefas é conter as angustias dos integrantes das equipes.Esse ponto é muito interessante. Em oposição ao imperativo patriarcal tradicional ou patriarcal de masculinidade que podemos observar no mundo dos petroleiros, onde a repressão das emoções resulta ser a condenação de um homem "fato e direito" (Palermo, 2017), nesses espaços de trabalho interpela-se aos homens a não bloquear os sentimentos e, sobretudo a serem objetivos. Demandam-se homens expressivos. Esse aspecto é paradoxo e sugestivo para a análise. Ao fortalecer umethos de masculinidade que robustece uma disciplina fabril, se desmontam ao mesmo tempo núcleos de sentidos de uma masculinidade "tóxica"fortemente fixada em nossas sociedades ocidentais, que contrasta radicalmente com a exacerbação da masculinidade que se exerce no mundo do petróleo. Ao contrário, desmontar essas práticas e representações de uma masculinidade tradicional que, como analisamos com os petroleiros, faz com que os fragilizem e não libera aos homens da indústria do software de diversos sofrimentos aos que são submetidos por um processo de trabalho que demanda outras maneiras de como se comportar como homens, inclusive não tradicionais. Nesse sentido, apela-se a formas de 
masculinidade de acordo com os requerimentos da produção e, o chefe de equipe constitui-se como uma das principais roldanas de transmissão de controle da dinâmica laboral.

A capacidade de trabalhar não brota de forma "natural" senão que deve ser socialmente produzida. E, nesse sentido, interpela-se um particularethosda masculinidade que desmonta certos elementos de um modelo patriarcal, mais não no sentido da liberação do coletivo de trabalho, senão para fortalecer uma determinadadisciplina fabril.Archettinos lembra de que a masculinidade é um processo de tensão e negociação constante em função dos modelos bem sucedidos de como ser homens(1999: 157). Na indústria vinculada a produção de bens informacionais, o modelo de bem sucedido de homem vincula-se com modelos radicalmente opostos aos do mundo petroleiro. Esses atributos da masculinidade transtornam certos valores tradicionaise/ou patriarcais. Ao contrário, consolidam práticas e representações de acordo a uma disciplina fabril que não deixam isentos aos trabalhadores de sexo masculino de diversos sofrimentos produto do processo de trabalho.

\section{ConsideraçõesFinais}

Reflexionardesde a antropologia do trabalho com respeito das problemáticas que foram, em grande medida, investigadas por estudos de gênero e, em particular, pelos estudos referentes às masculinidades é uma tarefa muito gratificante e frutífera. Em primeiro lugar, porque a proposta de colocar em diálogo os estudos do trabalho com os estudos das masculinidades nos permite problematizar interrogantes a respeito de como os homens "fazem" -e não fazem-tendo em conta os processos laborais como elementos chaves na configuração da masculinidade. $\mathrm{E}$ em segundo termo, porque levando adiante uma análise que desnaturaliza os interesses e peleja vinculado com uma relação difícil capital-trabalho, fazendo foco nas relações entre a masculinidade e as pretensões concretas das constituições hegemônicas empresariais para construir subjetividades obreiras.

Em linhas gerais, o aporte problemático que aqui compartilhamos sublinhaque é indispensável pensar nas relações de gênero de maneira indiscutível dos sistemas produtivos. E nesse sentido, afirmamos como tese principal que as construções hegemônicas nos espaços de trabalho mobilizam e interpelam configurações de gênero como parte de um processo que entranha uma racionalidade instrumental. Através da consolidação dadisciplina fabrilsedinamizam diversas posições de gênero segundo os requerimentos dos processos de trabalho. 
De tal maneira, é possível interpelar posições tradicionais a respeito $\mathrm{da}$ masculinidade inclusive masculinidades destrutivas. Quer dizer, todas as construções genéricas, inclusive as que não são normativas, podem encontrar um lugar instrumental sob o sol do capitalismo. A comparação entre ambos os casos nos permite chegar a essa conclusão preliminar: enquanto que a indústria petroleira se maximiza modelos de masculinidade tradicionais, nas fábricas de software se dinamiza um ethos da masculinidade que se contrapõe com os modelos tradicionais de como se comportar como homens. Ao contrário, Essa perda de certos elementos de uma masculinidade hegemônica fortalece o império do processo de trabalho.

Para finalizar, encerramos com uma frase de Silvia Federicido livro Calibán y labruja:“(...)o gênero não deveria ser considerado uma realidade puramente cultural senão que deveria ser tratado como uma especificação das relações de classe”. (2014: 27).

\section{Referências}

Archetti, E. (1999), Masculinidades. Fútbol, tango y polo enla Argentina. Argentina, Editorial Antropofagia.

Bastos, S. (1998), "Desbordando patrones: el comportamiento doméstico de los hombres", en La Ventana, No. 7, pp. 166-224.
Braverman, H. (1974), Trabajo y capital monopolista, México, Nuestro Tiempo.

Burawoy, M. (1989), El consentimiento en la producción,Madrid,Ministerio de Trabajo y Seguridad Social.

Connell, R. (1995), Masculinities, Berkeley, University of California Press.

Eckert, C. (2012),Memória e trabalho; etnografía da duração de umacomunidade de mineiros de carvão (La Grand-Combe, França),Curitiba,Appris.

Federici, S. (2014), Calibán y la bruja. Mujeres, cuerpo y acumulación originaria. Madrid, Traficantes de Sueños.

Figueroa, P., Juan Guillermo (2005), "Elementos para elestudio de lasexualidad y lasalud de losvarones integrantes de lasFuerzas Armadas", enPantelides, Edith Alejandra y López, Elsa (Comp.), Varones Latinoamericanos, Buenos Aires, Paidós, pp. 47-80.

Fonseca, C. (2003), "Philanderers, Cuckolds and WilyWomen: ReexaminingGenderRelations in a BrasilianWorking-Class

Neighborhood", en Gutmann, Matthew C. (Edit.). Changing Men and Masculinities in Latin America, Durham and Londres, Duke University Press.

Fuller, N. (1997), "Fronteras y retos: Varones de clase media delPerú", enValdés, Teresa y Olavarría, José (Edit.), Masculinidad/es. Poder $y$ crisis, Santiago de Chile, Isis Internacional, pp. 139-153.

Gaudemar, J.P. (1991), El orden y la producción. Nacimientos y formas de 
la disciplina de fábrica, Madrid, Trotta.

Gilmore, D. (1994), Hacerse hombre: concepciones culturales de la masculinidad, Barcelona, Paidós.

Kaufman, M. (1995), "Los hombres, el feminismo y las experiencias contradictorias del poder entre los hombres", en Género e identidad, Bogotá, Tercer Mundo Editores, pp. 34-64.

Kazandjian,

$\mathrm{R}$.

(2017),

"Desempeñarlamasculinidad", enNo nacemos machos. Cinco ensayos para repensar el ser hombreenel patriarcado, Ciudad de México, Ediciones La Social, pp. 15-23.

Kimmel, M. (1997), "Rethinking 'Masculinity': New Directions in Research", en Kimmel, Michael (Ed.), Changing Men: New Directions in Research on Men and Masculinity, Newbury Park CA, Sage, pp. 9-24.

Laqueur, T. (1994), La construcción del sexo, Barcelona, Cátedra.

LeiteLopes, J. S. (2011), El vapor deldiablo. El trabajo de losobrerosdelazúcar, Buenos Aires, Antropofagia.

Mura, N.; Yansen, G.; Zukerfeld, M. (2012). “¿Por quélasmujeres no programan? Acerca de los vínculos entre género, tecnología y software", enDughera, Lucila; Yansen, Guillermina y Zukerfeld, Mariano (Comp.) Gente con códigos. La heterogeneidad de losprocesosproductivos de software. Buenos Aires, Argentina, UniversidadMaimónides, Editorial Científica y Literaria, pp. 237-278.

Nash, J. (2015),Hegemonía empresaria en Estados Unidos. Claves para una etnografía de los ciclos industrialesenlas comunidades urbanas,Argentina, Editorial Antropofagia.

Neiburg, F. (1988), Fábrica y Villa Obrera: historia social y antropología de los obreros del cemento. Tomos $1 \mathrm{y}$ 2. Biblioteca Política Argentina. Buenos Aires, Centro Editor de América Latina.

Palerm, Á. (1980), Antropología y Marxismo, México, CIS-INAHEditorial Nueva Imagen.

Palermo, H. M. (2012), Cadenas de oro negro en el esplendor y ocaso de YPF, Buenos Aires, Antropofagia.

Palermo, H. M. (2017), La producción de la masculinidad en el trabajo petrolero. Buenos Aires, Editorial Biblos.

Ribeiro, G. L. (1991) Empresas transnacionais. Um grande projeto por dentro. Brasil, Marco Zero e Anpocs.

Ribeiro, G. L. (2006) El capital de la esperanza. La experiencia de los trabajadores en la construcción de Brasilia., Buenos Aires, Antropofagia

SariegoRodríguez, J. L. (1988), Enclaves y mineralesenel norte de México. Historia social de losmineros de Cananea y Nueva Rosita. 1900-1970, México, Ediciones de la Casa Chata, CIESAS.

Scott, J. W. (2008), "El género: Una categoría útil para el análisis histórico", en Lamas, Marta (Comp.), El género: la construcción cultural de la diferencia sexual. México, PUEG, pp. 265-302. [(1986) “Gender: A Useful Category of Historical Analysis", en American Historical Review, No. 91, pp. 1053-1075]. 
Soul, J. (2014), Somiseros, La configuración y eldevenir de un grupo obrero desde una perspectiva antropológica, ProhistoriaEdiciones, Rosario.

Viveros Vigoya, M. (2001), "Masculinidades. Diversidades regionales y cambios generacionales en Colombia", en Viveros Vigoya, Mara; Olavarría, José y Norma Fuller (Comps.), Hombres e identidades de género. Investigaciones desde América Latina. Colombia, Universidad Nacional de Colombia, pp. 35-153.
Young, I. (1992), "Marxismo y Feminismo: más allá del 'matrimonio infeliz' (una crítica al sistema dual)", enEl Cielo por asalto, Año II, No. 4. [Primeraedición1981] Disponível em:http://www.democraciasocialista.o rg/wpcontent/uploads/2014/03/139104361Young-Marxismo-y-feminismo.pdf

Data de Submissão: 26/07/2018

Data de Aceite: 29/10/2018 